\title{
Life Satisfaction of International Students: Intercultural Sensitivity and Knowledge Sharing Attitude as Determinants
}

\author{
Wang Lulan", Priyadarshini Muthukrishnan,", Irudhaya Mary ${ }^{3}$ \\ ${ }^{1}$ Institute of Graduate Studies, SEGi University, Selangor, Malaysia \\ ${ }^{2}$ Faculty of Behavioural Sciences, Education and Languages, HELP University, Selangor, Malaysia \\ ${ }^{3}$ Department of English Education, Stella Matutina College of Education, Chennai, India
}

Received March 21, 2020; Revised April 17, 2020; Accepted May 3, 2020

Copyright $\bigcirc 2020$ by authors, all rights reserved. Authors agree that this article remains permanently open access under the terms of the Creative Commons Attribution License 4.0 International License

\begin{abstract}
The growing multicultural environments of higher learning institutions have broadened the scope of cultural interactions among students of diverse cultural backgrounds. The current study attempted to investigate the influence of the intercultural sensitivity and knowledge sharing attitude on life satisfaction of international students in three private universities in Malaysia. The study adopted quantitative research methods, and the sample for the study were 300 international students in the undergraduate programme. Correlation and multiple regression analyses were conducted to examine the relationship between predictors and life satisfaction. The final regression model revealed that $22.72 \%$ of the variance in life satisfaction of international students could be explained by the predictor variable intercultural sensitivity while knowledge sharing attitude did not contribute to the regression model. The study has brought new insights into understanding the life satisfaction of international students. The study concluded with relevant recommendations that are needed to be implemented to improve the intercultural sensitivity, knowledge sharing attitude and life satisfaction of international students.
\end{abstract}

Keywords Intercultural Sensitivity, Knowledge Sharing, Interaction Enjoyment, International Students, Attitude towards Knowledge Sharing

\section{Introduction}

Over the past decades, due to globalisation and the knowledge-driven economy, the education industry has experienced a rapid uplift in the internationalisation of higher education. The emergence of knowledge-driven economy has allowed educational institutions to be more open for international students in pursuing their higher education and preparing them for the future workforce demands. Internationalisation of higher education has contributed to the socio-economic development of the country by generating substantial scale revenues and employment in the international market. Organisation for Economic Cooperation and Development (2009) reported that global higher education is paramount and international student mobility is the primary form of cross-border higher education. Due to the significant flow of international students, higher learning institutions derive international character with social responsibilities in strengthening the cultural ties to broaden the scope of cultural interactions among students from diverse cultural backgrounds. In this perspective, intercultural sensitivity encourages international students to adopt enthusiastically to their environment, and the attrition rate of these students could be avoided. However, empirical evidence has shown that international students are confronted with multifaceted challenges in their acculturation process related to cultural values, beliefs and culture of the host country. Therefore, raising intercultural sensitivity of international students enhances their ability to make meaningful interpretations of the culture, norms, values and community practices which ascertain satisfied life during their interim of stay in the host country.

De-Andrés (1999) emphasised that students develop positive self-esteem based on their environment, life experiences, and how others perceive them. The international students adapt and integrate themselves to the social, psychological, academic, cultural and organisational setting of the university (Rienties et al., 2012). The social integration involves developing interpersonal relationships in the unique intercultural space within and outside classrooms and experiencing a positive relationship with 
culturally diverse people. Furthermore, feelings of international students in terms of acceptance, inclusion and recognition in classroom interaction are essential to strengthen their interpersonal relationships (Mak, Bodycott, \&Ramburuth, 2015). Knowledge sharing of international students differ from domestic students in many ways. Chen et al., (2017) findings highlighted two main reasons for the international students to share knowledge with other students viz., to strengthen their knowledge quality and to make new friends. Besides, his study reported that language barriers and cultural differences are the two hindering factors for knowledge sharing. In the same vein, Vazirani et al., (2018) concluded that communication difficulties and a lack of support in the classroom affect international students' life satisfaction which consequently leads to decreased contact with local students and maladjustment in the host culture. To promote intercultural interactions, universities are adopting peer-pairing programs which allow substantial interaction between the international and domestic students (Summers \& Volet, 2008). Ryff (1989) noted that well- being is positively correlated to positive relations and cultural empathy. Presumably, international students are regarded as rich sources of international education, adding cultural diversity to universities, student culture and contributing to the intellectual life of universities.

The interaction and knowledge sharing between international and domestic students can be regarded as an intellectual discourse which allows them to share values, beliefs, information and ideas, consequently leading to strengthen intercultural relationships. Currently, many researchers examined the issues and challenges faced by international students and elucidated the factors affecting their psychological and academic life. However, there is a dearth of studies in examining the relationship between the three variables of the study. Therefore, the current study is aimed to examine how intercultural sensitivity and knowledge sharing attitude affect the satisfaction of life of international students.

\subsection{Research Problem}

Studies from several countries have examined the issues and challenges confronted by international students in adapting themselves to the new culture, environment and academic demands (Smith \& Khawaja, 2011; Desa, Yusooff, \& Kadir, 2012). According to Chen (1996), academic stress is a common stressor among international college students in North America, and his study reported that the students have a substantial level of psychological stress. Several studies have shown evidence that unfamiliar culture, limited language proficiency and performance expectations were common stressors among university students (Kosheleva, Amarmor, \& Chernobilsky, 2015; Misra \& Castillo, 2004). In the same vein, studies conducted in Malaysia, have confirmed the challenges faced by international students highlighting that international students are challenged with multifaceted problems at varying degrees that affect their overall life satisfaction. These studies reported problems related to culture, climate, and care, cost of living (Malaklolunthu\&Selan, 2011; Asgari\&Borzooei, 2014), the livelihood service, and facilities (Yee \& Mokhtar, 2013). Adding to that, Singh, Schapper\& Jack (2014) reported that international students in Malaysia who face adjustments and psychological problems at academic, social or personal levels had shown a negative relationship with their academic performance.

The Ministry of Higher Education in Malaysia has implemented strategic measures to raise the standards of internationalisation of higher education and to develop Malaysia as a potential educational hub (National Higher Education Strategic Plan, 2007-2020). The internationalisation of higher education has contributed a significant rise in the influx of international students in Malaysia confirming that there was a progressive increase in the enrollment of the international students from 35,000 in the year 2003 to 200,000 in 2017 (The Ministry of Higher Education, 2017). Malaysia is aiming to double the enrollment of the international students to 250,000 by 2025 and to achieve this expected increase of students' enrollment, the government, educational stakeholders and the higher learning institutions have to strategic measures to attract, retain and increase the enrollment by providing world-class education. Most of the international students migrating to Malaysia are from Southeast Asia, Middle Eastern and Middle Asia, African countries, and a minimal number from European countries. Although there is a prominent rise in the enrollment of international students, a substantial number of studies have identified the persistent problems faced by international students.

The importance of interaction and communication in multicultural settings has been widely investigated. Knowledge sharing allows students to facilitate interaction in the classroom, which was built a collegial relationship and acceptance among the students from the diverse cultural background. According to Sosik (2002), in multicultural settings, people bring their own cultural beliefs and expectations, and this largely influences the dynamics of interactions. Mallasi \& Ainin (2015) reported that non-monetary factors which include interpersonal trust, sense of enjoyment in helping others and self-efficacy were significant determinants of knowledge sharing behaviour of postgraduate students. From a broader perspective, knowledge sharing is a reciprocal act of giving and receiving or exchange of knowledge and is a mutual relationship that connects individuals to create a social-emotional network which maintains and strengthens social-emotional connections, provides implicit rewards of admiration, appreciation and friendliness (Bartol \& Srivastava, 2002). Taken together, these studies support the notion that knowledge sharing in academic settings contributes to one's self-fulfilment, a sense of enjoyment in helping peers and to build trust and relationship. 
To summarise, a wealth of research on international students primarily focused on the factors that affect their cultural and academic adaptation and academic performance. However, far too little attention has been paid to study the relationship between knowledge sharing attitude, intercultural sensitivity and life satisfaction. Therefore, the current study seeks to provide empirical findings and recommendations to attend to the needs of international students for their enhanced learning experiences and life satisfaction during their interim stay in the host country. Therefore, the current research will address the following research questions.

1. What is the level of intercultural sensitivity among international students?

2. What is the level of knowledge sharing attitude among international students?

3. What is the level of life satisfaction among international students?

4. Are there significant relationships between intercultural sensitivity, knowledge sharing attitude and life satisfaction of international students?

5. To what extent do intercultural sensitivity and knowledge sharing attitude predict life satisfaction of international students?

\section{Literature Review}

\subsection{Intercultural Sensitivity}

A line of intercultural studies has conceptualised the terms intercultural sensitivity, intercultural communicative competence, transcultural communicate competence interchangeably (Sinicrope, Norris, \& Watanabe, 2007). The conceptual ambiguity and lack of consensus in the definition of the term intercultural sensitivity have been widely discussed across many studies. The various models of intercultural sensitivity have varied theoretical perspectives, and the views are multifold. Literature shows there are five different models of intercultural sensitivity, such as adaptational (Kim, 1988), developmental (Bennett, 1993), co-orientational (Byram, 1997), compositional (Deardorff, 2006) and causal (Arasaratnam, 2006). However, Bennett (1993) developmental model of intercultural sensitivity shows the progression from the ability to transform one's views of the world (ethnocentric) toward increasing cultural awareness and competence (ethnorelative) primarily through six successive developmental stages. Chen and Starosta (2000) criticised that earlier models failed to demonstrate the differences between the constructs intercultural competence and intercultural sensitivity and argued that intercultural sensitivity is the prerequisite to develop intercultural competence, and the later has the combined features of both cross-cultural attitude and behavioural skills. Among the line of studies in intercultural sensitivity, the model which gained much attention and widely accepted is Chen and
Starosta (1996) model of intercultural sensitivity. According to Chen and Starosta (1996), the overarching construct intercultural communication is an umbrella term which includes cognitive, affective and behavioural skills of interactions as intercultural awareness, intercultural sensitivity, and intercultural communicative adroitness respectively. These three dimensions are distinct in terms of functions and skills and are closely related. Intercultural awareness represents the cognitive dimension of intercultural communication competence which refers to an individual competence to comprehend and explain the similarities and differences of others' cultures. Intercultural awareness comprises of two components: self and cultural awareness. The term intercultural sensitivity which is the affective component of intercultural communication competence is the central focus of this research, and it refers to the positive emotional desires of a person in understanding, acknowledging, appreciating, and accepting cultural differences that promote intercultural communicative competence. It demonstrates the ability of the person to receive and respond to the positive aspects before, during and after intercultural interaction.

Drawing evidence from earlier studies, Chen and Starosta (1996) initially conceptualised intercultural sensitivity and made the first attempt in the construction and validation of the instrument to measure intercultural sensitivity. Their validation study was done on the US sample of college students, which resulted in the five-factor model for IS instrument. The 24 items scale explained a total of $37.3 \%$ variance under five dimensions and the internal consistency was reported as 0.88 . The scale identified five interrelated dimensions: interaction engagement, respect for cultural differences, interaction confidence, interaction enjoyment, and interaction attentiveness. Fritz et al., (2002) replicated the study on German samples and reported five-factor model using confirmatory factor analysis. Peng (2006) and Peng, Rangsipahat, and Thaipakdee (2005) reported the scale was reliable but did not establish the validity of the scale. However, a subsequent study by Friz, et al., (2005) on American and German samples failed to reproduce the five-factor model raising ambiguity and concerns over validity on the five-factor model. Taman (2010) validated the scale using undergraduate students sample in Malaysia and reported the three-factor structure of intercultural sensitivity under three dimensions which includes interaction attentiveness and respect, interaction openness, and interaction confidence. There are contradictory viewpoints on the model of intercultural sensitivity, whether it as a generic or culture-free model. Empirical evidence, particularly from non-western countries (Tamam 2010; Wu 2015) supported the culture-free scale for measuring intercultural sensitivity. Therefore, Chen and Starosta (1996) model of Intercultural sensitivity needs further theoretical validation and empirical support

\subsection{Knowledge Sharing}

Learning is a collaborative activity, and the university 
students are required to engage in the knowledge sharing process proactively. The literature review has identified multifaceted views on knowledge sharing. Chong, Teh and Tan (2014) highlighted that the significant element involved in knowledge sharing is the willingness to engage in meaningful learning. Dokhtesmati and Bousari, (2013) conceptualised knowledge sharing as a cooperative process in the distribution of concepts, skills and information. In the same lines, Davenport and Prusak (2000) considered it as a collaborative activity which involves knowledge exchange between individuals and groups of people. Knowledge sharing is considered as the transfer of knowledge while engaging in some cooperative activities which allow mutual interaction among the participating individuals. Knowledge sharing differs from the notion of information sharing in the view that knowledge sharing has the component of reciprocity, which involves an exchange of information (Connelly \& Kelloway, 2003). Further, it refers to the interest of an individual to share their knowledge with others in which one shares knowledge is referred to as a knowledge contributor while the other who receives knowledge is the knowledge recipient.

In similar perspectives, Gupta and Govindarajan (2000) theorised that knowledge sharing encompasses five elements: the value of the source knowledge, media richness of the communication channel, the willingness of the source to share knowledge, willingness of the recipient to acquire knowledge and the absorptive capacity of the recipient. Besides, knowledge sharing is conceptualised as enjoyment in sharing knowledge and in helping others with the perception of altruistic principles which is attributed to intrinsic enjoyment in practising knowledge sharing (Davenport \& Prusak, 1998).

The theory of reasoned action defined attitude as an individual's intention to engage in a specific behaviour (Ajzen \& Fishbein, 1980). Knowledge sharing attitude refers to an individuals' intention in mutual sharing knowledge with others. Chong, Teh and Tan (2014) viewed that the essential element in the knowledge sharing process among university students is a voluntary and active sharing of knowledge for meaningful learning. Research findings have confirmed that knowledge sharing has improved learning outcomes and self-development (Majid \& Wey, 2011), critical thinking skills (Sim, 2006), reflective practices and positive learning outcomes and cognitive gains (Rafeli \& Ravid, 2003). Knowledge sharing encompasses both individual and communal responsibilities in creating new knowledge, gaining skills and in the understandings of attitudes and values of other culture.

Studies have identified potential barriers which impede knowledge sharing among students include lack of trust and interpersonal relationship, lack of reciprocity and trust, lack of in-depth relationship between the source and the recipient of knowledge (Yuen \& Majid, 2007), lack of knowledge sharing culture in the learning environment and lack of motivation. Further, Yuen \& Majid (2007) confirmed that competitive mindset inhibits knowledge sharing behaviour of students. These findings confirmed that mutual trust and interpersonal relationship are key determinants in knowledge sharing behaviour among students. In the current study, knowledge sharing attitude refers to the intention of the international students to engage in knowledge sharing activities which specific focus on the face-to-face classroom interaction that occurs in the academic settings related to their programme of study.

\subsection{Life Satisfaction of International Students}

Life satisfaction is a generic concept that represents an individual's contentment with their own life. It is considered as one of the indicators which determine the quality of life, which includes physical, social, emotional and mental health. Several researchers have agreed with the conception that life satisfaction is subjective, evaluative and judgmental. Over the past decade, much attention has been on studying life satisfaction of individuals in various contexts, and the studies have conceptualised life satisfaction in multiple ways. However, there are certain consensus in the conceptualisation of life satisfaction. Numerous studies have conceptualised it as a self- appraisal process by which a person compares and assess one's conditions of existence or quality of life with the self-referenced standards or chosen criteria (Diener et al., 1985). Diener Oishi and Lucas (2003) noted that less the variability or the incongruence between the achievement and desire, more significant is the sense of life satisfaction. Daig, Herschbach, Lehmann, Knoll, and Decker (2009) conceptualised it as a cognitive appraisal of one's life situation with the different domains of life.

Further, earlier studies have reported life satisfaction as an integral part of well-being, which is evaluative in terms of cognitive or judgmental components of subjective wellbeing. While the other components of subjective well- being are positive and negative effects which are related to the affective and emotional aspects of well- being. Though there exists substantial correlation among the three components of subjective well- being, each component is unique and need to study in its own. Although the literature expands knowledge on life satisfaction of the international students in multiple perspectives, due to the over aching nature and conceptual broadness (Erdogan et al., 2012) of life satisfaction, there are still many factors that need to be investigated (Suh et al., 1998).

\section{Materials and Methods}

This study used a quantitative approach to investigate the influence of intercultural sensitivity and knowledge sharing attitude on life satisfaction of international students in universities.

\subsection{Population and Sample}

The population for the study is the international students 
pursuing their undergraduate programmes from three private universities in Malaysia. The Malaysian Ministry of Higher education (2015) report indicated that a much higher number of undergraduate international students were enrolled in private universities compared to public universities. Therefore, to maintain the homogeneity of the sample, the present study focused on international students in private universities. A sample of 300 international students was selected for the study using random sampling. In selecting the sample, the researcher considered the list of classes available to take part in the survey. Following that, the researcher randomly selected the classes, and the survey instruments were given to the international students from the selected classes. The research has been taken due consideration to select a sample with a various demographic profile of the international students. Descriptive analysis of the sample of 300 international students showed that 162 $(54.0 \%)$ are male and the remaining $138(46 \%)$ are female students; $178(59.33 \%)$ are in the age range $18-22$ years, while $108(36 \%)$ of the total sample are from the age range of $23-27$ years and $4.67 \%$ (14) students are between the age range of 28-32 years. Further, analysis of data shows that $183(61 \%)$ students are Chinese, $8(2.67 \%)$ students are Indians, $26(8.67 \%)$ students are Koreans, 39 (13\%) students are Japanese, $13(4.33 \%)$ of them are from Bangladesh, and $10(3.33 \%)$ of them are from Africa while 21 Arab students accounted for $7.00 \%$ of the total sample. The distribution of respondents by the programme of the study showed that majority $85(28.37 \%)$ of the students are majoring in IT programme, $60(20 \%)$ students are doing education programmes, and $52(17.33 \%)$ students are in management programmes. The remaining 43(14.33\%) students are majoring in various Engineering programmes.

\subsection{Data Collection Tools}

The research instruments used in the study consist of two sections. Section A of the questionnaire focused on demographic variables of the participants while section B of the questionnaire measures the three main variables of the study: intercultural sensitivity, knowledge sharing attitude and life satisfaction of the students. The demographic details of the students include gender, age, nationality, major of study and duration of stay in Malaysia.

\subsubsection{Intercultural Sensitivity Scale}

To study the intercultural sensitivity of the international students, the researchers adapted the research instrument developed by Chen \& Starotsa (2000) and Taman (2010). In the current study, the factor analysis identified two factors, namely, respect for cultural differences and intercultural interaction competence. The instrument has 15 statements, and the participants' responses were collected using a 5-point Likert scale which has the options ranging from disagree to agree. Cronbach alpha reliability coefficient for the two subscales: respect for cultural differences and intercultural interaction competence were found to be 0.85 and 0.82 respectively. The Cronbach alpha reliability coefficient for the overall scale was 0.87 .

\subsubsection{Knowledge Sharing Attitude}

To investigate the knowledge sharing attitude of international students, the general attitude towards knowledge sharing scale developed and validated by Yuen and Majid (2007) was considered. The scale has seven items for which the respondents have to record their responses across a five-point Likert rating scale. The reliability coefficient of the scale was found to be 0.850 .

\subsubsection{Satisfaction with Life}

To measure the life satisfaction of the international students, 'Satisfaction with Life Scale' (SWLS) developed by Diener et al. (1985) was used. SWLS is a short scale consisting of five items which are designed to measure the cognitive judgments of satisfaction with one's life. The literature review showed that many studies have extensively used it, to measure the life satisfaction of the university students and have shown high reliability scores. In the present study, the Cronbach alpha reliability coefficient for the scale was calculated as 0.880 .

\subsection{Data Collection \& Data Analysis}

Data was collected from three private universities in Selangor in Malaysia. Prior to data collection, the researchers sought permission from the Head of the department and the lecturers. The participants were informant about the consent, general information and guidelines before administering the survey. The students completed the survey in 20 minutes, and the data was collected across six weeks during the semester.

The research employed SPSS to analyse the data. To answer the first three questions, descriptive statistics were carried out. The research question four used Pearson's correlational analysis and following that multiple regression analysis was conducted to answer the research question five.

\section{Findings}

\subsubsection{Level of Intercultural Sensitivity among international} students

The mean and standard deviations of the data were calculated for the intercultural sensitivity as shown in Table 1. Descriptive findings in Table 1 show that the mean scores of the items range from 3.31 to 3.44 and most of the items reported average mean score. The findings revealed that the level of respect for cultural differences (Mean= 3.40, $\mathrm{SD}=.645)$ is average and intercultural interaction competence (Mean $=3.41, \mathrm{SD}=.636$ ) is slightly to the higher level. Finally, the overall mean of intercultural sensitivity is 3.405 with a standard deviation of .641 . 
Table 1. Intercultural sensitivity of international students

\begin{tabular}{|c|c|c|}
\hline Intercultural sensitivity & Mean & SD \\
\hline $\begin{array}{l}\text { I respect the beliefs and values of people from } \\
\text { different cultures. }\end{array}$ & 3.41 & .725 \\
\hline $\begin{array}{l}\text { I am open-minded to people from different } \\
\text { cultures. }\end{array}$ & 3.40 & .675 \\
\hline $\begin{array}{l}\text { I do not jump to concussions/judgments } \\
\text { immediately about people from different cultures. }\end{array}$ & 3.42 & .660 \\
\hline $\begin{array}{l}\text { I respect the ways people from different cultures } \\
\text { behave. }\end{array}$ & 3.40 & .601 \\
\hline $\begin{array}{l}\text { I am very observant when interacting with people } \\
\text { from different cultures. }\end{array}$ & 3.42 & .608 \\
\hline I think my culture is better than other cultures. & 3.43 & .697 \\
\hline $\begin{array}{l}\text { I enjoy the cultural differences that exist among } \\
\text { friends from different cultures. }\end{array}$ & 3.31 & .659 \\
\hline $\begin{array}{llllll}\text { I think people from other cultures are } \\
\text { narrow-minded. }\end{array}$ & 3.43 & .538 \\
\hline Respect for cultural differences & 3.40 & .645 \\
\hline $\begin{array}{l}\text { I don't like to be with people from different } \\
\text { cultures. }\end{array}$ & 3.40 & .642 \\
\hline $\begin{array}{l}\text { I often get discouraged when I am with people } \\
\text { from different cultures. }\end{array}$ & 3.35 & .608 \\
\hline $\begin{array}{l}\text { I get upset easily when interacting with people } \\
\text { from different cultures. }\end{array}$ & 3.43 & .675 \\
\hline $\begin{array}{l}\text { I feel confident when interacting with people } \\
\text { from different cultures. }\end{array}$ & 3.44 & .676 \\
\hline $\begin{array}{l}\text { I avoid those situations where I will have to deal } \\
\text { with culturally-distinct persons. }\end{array}$ & 3.43 & .727 \\
\hline $\begin{array}{l}\text { I am pretty sure of myself in interacting with } \\
\text { people from different cultures. }\end{array}$ & 3.41 & .696 \\
\hline $\begin{array}{l}\text { I can be as sociable as I want when interacting } \\
\text { with people from different cultures }\end{array}$ & 3.40 & .430 \\
\hline Intercultural interaction competence & 3.41 & 0.636 \\
\hline Overall Intercultural sensitivity & 3.405 & 0.641 \\
\hline
\end{tabular}

(Scale: $1=$ Strongly disagree; $2=$ Disagree; $3=$ Neutral; 4=Agree; $5=$ strongly agree)

\subsubsection{Level of Knowledge Sharing Attitude among International Students}

Knowledge sharing attitude of the international students was investigated using nine items and the item-wise descriptive analysis is presented in Table 2 . The descriptive findings in Table 2 show that 3 items reported low level while 4 items showed a high level of knowledge sharing attitude. The findings concluded that the overall knowledge-sharing attitude of the international students was averaged at 2.95 with a standard deviation of .580 .
Table 2. Knowledge sharing attitude of international students

\begin{tabular}{|l|l|l|}
\hline Knowledge Sharing Attitude & Mean & SD \\
\hline $\begin{array}{l}\text { I feel that it is important to share knowledge } \\
\text { with other students for the benefit of all. }\end{array}$ & 3.52 & .593 \\
\hline $\begin{array}{l}\text { Many students feel that the lecturer might } \\
\text { penalise them for sharing information and } \\
\text { knowledge. }\end{array}$ & 2.20 & .482 \\
\hline $\begin{array}{l}\text { Students should share knowledge with their } \\
\text { peers only when approached }\end{array}$ & 3.62 & .496 \\
\hline $\begin{array}{l}\text { It is better to avoid sharing information with } \\
\text { peers. }\end{array}$ & 2.11 & .698 \\
\hline $\begin{array}{l}\text { I feel that it is important to share knowledge } \\
\text { with other students for the benefit of all. }\end{array}$ & 3.57 & .520 \\
\hline $\begin{array}{l}\text { Many students have the mindset that sharing } \\
\text { knowledge is a type of plagiarism. }\end{array}$ & 2.12 & .592 \\
\hline $\begin{array}{l}\text { Knowledge sharing takes place when students } \\
\text { care about the needs of others. }\end{array}$ & 3.54 & .680 \\
\hline Overall Knowledge Sharing Attitude & 2.95 & .580 \\
\hline
\end{tabular}

(Scale: $1=$ Strongly disagree; $2=$ Disagree; $3=$ Neutral; $4=$ Agree; $5=$ strongly agree)

\subsubsection{Level of Life Satisfaction among International Students}

Table 3 shows the results for the life satisfaction of international students In overall, international students showed a high level of life satisfaction (Mean=3.51, $\mathrm{SD}=.663$ ). From the table, the highest mean score was recorded for the item "The conditions of my life are excellent" (Mean= 3.55, $\mathrm{SD}=.753$ ). Meanwhile, the lowest mean score was recorded for the item "So far, I got all the important thing I want in life" (Mean= 3.46, $\mathrm{SD}=.456$ ) but the item still fell under high level of agreement. In sum, these results show that international students are highly satisfied with their life.

Table 3. Life Satisfaction of international students

\begin{tabular}{|l|c|c|}
\hline $\begin{array}{l}\text { If I could live my life over, I would change almost } \\
\text { nothing. }\end{array}$ & 3.54 & .771 \\
\hline Everything in my life is as I wanted. & 3.50 & .626 \\
\hline So far, I got all the important thing I want in life. & 3.46 & .456 \\
\hline The conditions of my life are excellent. & 3.55 & .753 \\
\hline I am satisfied with my life. & 3.52 & .711 \\
\hline Overall life satisfaction & 3.514 & .663 \\
\hline
\end{tabular}

(Scale: $1=$ Strongly disagree; $2=$ Disagree; $3=$ Neutral; $4=$ Agree; $5=$ strongly agree) 


\subsubsection{Relationships between Intercultural Sensitivity,} Knowledge Sharing and Life Satisfaction among International Students

To study the relationship between the variables of the study, correlation analysis was carried out and the results are shown in the below Table 4. Correlations were computed to study the relationship between intercultural sensitivity, knowledge sharing and life satisfaction of the students. The results concluded that the correlation between intercultural sensitivity and knowledge sharing $(\mathrm{r}=.198, \mathrm{p}$ $<.001)$ and students' life satisfaction $(r=.153, \mathrm{p}<.001)$ was positive, weak and significant, with respect to the relationship between knowledge sharing attitude and students' life satisfaction was not significant.

Table 4. Relationship between the variables

\begin{tabular}{|c|c|c|c|}
\hline Variables & 1 & 2 & 3 \\
\hline 1. Intercultural Sensitivity & 1 & & \\
\hline 2. Knowledge Sharing Attitude & $.198^{* *}$ & 1 & \\
\hline 3. Life Satisfaction & $.153^{* *}$ & .069 & 1 \\
\hline
\end{tabular}

\subsubsection{Regression of Intercultural Sensitivity, Interaction} Enjoyment in Knowledge Sharing and Knowledge Sharing Attitude on Life Satisfaction among International Students

To study the results of the prediction of the intercultural sensitivity and knowledge sharing attitude on student's life satisfaction, multiple regression analysis was conducted, and the results are presented in Table 5. The correlation between the predictor variables: intercultural sensitivity, and knowledge sharing attitude and the criterion variable life satisfaction of international students was found as 0.400 . The R2 value of .2272 in this model shows that $22.72 \%$ of the variance in the criterion variable was caused by changes in the predictor variables.

Table 5. Model Summary

\begin{tabular}{|c|c|c|c|c|}
\hline Model & $\mathrm{R}$ & $\mathrm{R}^{2}$ & Adjusted $\mathrm{R}^{2}$ & S.E \\
\hline 1 & $.400^{\mathrm{a}}$ & .2275 & .218 & 1.41933 \\
\hline
\end{tabular}

a. Dependent Variable: students' life satisfaction, ${ }^{*} \mathrm{p}<.05$

In the regression model, the two predictor variables were entered in a single block, of the multiple regression analysis. The ANOVA analysis results confirmed that the model is significant $[\mathrm{F}(4,295)=3.378, \mathrm{p}<.05]$.

According to Table 6, the coefficient values for the regression analysis concluded that only intercultural sensitivity $(\beta=.140 ; \mathrm{t}=2.385, \mathrm{p}<0.05)$ was a significant predictor of the students' life satisfaction while knowledge sharing attitude $(\beta=.067 ; \mathrm{t}=.908, \mathrm{p}=0.365)$ was not significant. This confirmed that the two variables contribute to the model and can explain about $22.75 \%$ of the variance in students' life satisfaction. However, knowledge sharing attitude does not make a significant contribution to the total variance and cannot explain the life satisfaction of the international students significantly. The regression Model for life satisfaction of the international students derived from the model is: students' life satisfaction $=3.851+.239$ (Intercultural sensitivity).

Table 6. The Results of Variance Analysis

\begin{tabular}{|c|c|c|c|c|c|c|}
\hline & \multirow{2}{*}{ Model } & \multirow{2}{*}{$\begin{array}{c}\begin{array}{c}\text { Unstandardized } \\
\text { Coefficients }\end{array} \\
\text { B }\end{array}$} & \multicolumn{2}{|c|}{$\begin{array}{l}\text { Standardized } \\
\text { Coefficients }\end{array}$} & \multirow{2}{*}{$t$} & \multirow{2}{*}{$p$} \\
\hline & & & S.E & Beta & & \\
\hline \multirow{3}{*}{1} & (Constant) & 3.851 & .781 & & 4.934 & .000 \\
\hline & $\begin{array}{c}\text { Intercultural } \\
\text { sensitivity }\end{array}$ & .239 & .058 & .140 & 2.385 & $.018^{*}$ \\
\hline & $\begin{array}{c}\text { Knowledge } \\
\text { sharing attitude }\end{array}$ & .067 & .169 & .024 & .394 & .694 \\
\hline
\end{tabular}

a. Dependent Variable: students' life satisfaction; ${ }^{*} \mathrm{p}<.05$

\section{Discussions and Implications of the Study}

The current research aimed to establish empirical evidence in the impact of intercultural sensitivity and knowledge sharing attitude on life satisfaction of international students. The results revealed that there is a significant positive relationship between intercultural sensitivity and life satisfaction and intercultural sensitivity is a significant predictor of life satisfaction. The findings confirmed that intercultural sensitivity promotes life satisfaction of international students. The findings are consistent with earlier empirical findings from several other studies which are related to the importance of mutual dialogic interaction and understanding of people in improving the stay fulfilment and overall life satisfaction of international students (Wilson et al., 2013). The international students seek to get clarity and achieve better cultural adaptation through mindful interaction with students from other cultural backgrounds. Sarwari and Wahab (2017) concluded that students' intercultural sensitivity and intercultural communication competence affect their daily personal and social lives in multiple ways. In the same vein, Maharaja (2018) concluded that studying abroad enhances intercultural competence in multiple ways, which includes gaining a better understanding of the host country culture, global-mindedness, patience, assertiveness, maturity, self-awareness, flexibility and adaptability.

In contrary to the expectations, this study found that knowledge sharing attitude is not a significant predictor of life satisfaction of international students. The plausible reasons could be attributed to the need for group cohesiveness and collaborative work among the students when they get involved in classroom discussions. According to Syed-Ihksan (2004), knowledge sharing improves group interactions, problem-solving, and decision-making skills of the students. Lack of friendship or familiarity with the peers inhibits the knowledge sharing practices. Few studies relating to life satisfaction, 
knowledge sharing, and interaction reported that knowledge sharing (Jiang, 2014), interpersonal relationships (Bosson et al., 2006) and social interactions (Wasko \& Faraj, 2005) were potential factors in promoting life satisfaction. The current findings contradict with the previous study findings on information sharing which showed a positive relationship with internal satisfaction (Lin, 2007; Wang \& Noe, 2010), perceived favourable life quality (Choi et al., 2014) and positive psychological state (Novak, 2000). There are several possible explanations for the unexpected results. One interesting reason could be attributed to the learning preference of digital natives. Knowledge sharing is considered as a collaborative effort in problem- solving and in the construction of new knowledge. Knowledge sharing involves helping tendency which requires mutual trust, reciprocity and collegial relationship. Due to the exponential growth and application of information and communication technology, there is a prominent shift in the teaching and learning processes at the higher learning institutions. Earlier studies have found that students are most likely to engage and learn through technology-enabled classroom interactions rather than conventional mode of face to face interaction and knowledge sharing (Yuen \& Masjid, 2007).

The use of formal learning management systems (Blackboard, Moodle), informal learning channels (blogs, google classroom, online tools) and other online interactive software facilitates learning and interaction among students in multiple ways that limit interaction and face to face communication. Shawaqfeh and Almahaireh (2019), confirmed that technowellness helps university students to use technology that consequently leads to better wellness which includes happiness and optimism. Further, studies have found that personality of students is a significant factor of learning style and knowledge sharing behaviour (Hsu, Wu \& Yeh, 2007; Huang, Davidso \& Gu, 2008; Gupta, 2008; Yuen \& Masjid, 2007). Knowledge sharing is strongly influenced by the willingness of an individual to engage in the interaction, openness and voluntary contribution of knowledge and ability to negotiate, refine and construct new knowledge. Yuen and Majid (2007) studied knowledge sharing patterns among university students and reported that students are positive towards peer learning and knowledge sharing, however when leaning activities are assessed and graded, the students show inhibitions in sharing knowledge due to the fear of outperformance of their peers. The findings from the current study can be utilised by the educational administrators, university counsellors and lecturers to gauge their understanding of international students and offer educational services that aim to promote life satisfaction of these students. Measures need to be taken to create a platform for interaction and knowledge sharing between the local and international students.

Few limitations of the current study must be acknowledged. The first limitation is the selection of the sample for the study. Although the sample was selected from three private universities and consisted of international students from various countries, it did not include international students from public universities in Malaysia and students pursuing graduate and doctoral studies. Therefore, caution must be exercised in the interpretation of the findings and results. Secondly, the study is cross-sectional research and has adopted quantitative research methods to address the research questions. In the future, a longitudinal study can be undertaken with a focus on investigating the changes in intercultural sensitivity and knowledge sharing of international students, using time-series data could bring more insights into understanding the acculturation process. Thirdly, the instruments used in the study are self- reported measures, so there is room for social comparison of norms and practices which would have affected the overall findings. Future studies could be undertaken to examine the research problem using qualitative or mixed research methods. Finally, this study is focused on international students who are adjusting to one particular culture of the host country. Future research can consider the interplay of the demographic variables, mediators and moderators in the relationships of the variables of the current study.

\section{Conclusions}

In a nutshell, the current study presented the cross-sectional and empirical evidence for the life satisfaction of international students in relation to their intercultural sensitivity and knowledge sharing attitude. The findings concluded that the intercultural sensitivity and knowledge sharing were moderate while life satisfaction of international students was high. The results confirmed that intercultural sensitivity influences the life satisfaction; however, knowledge sharing behaviour did not significantly influence the life satisfaction of the students. Despite the limitations of the study, the study has brought valuable insights to the existing literature in terms of identifying the need for improving the intercultural sensitivity, life satisfaction and knowledge sharing among the international students. The study has put forth recommendations stressing the importance of institutional and national initiatives to organise activities that allow interaction of the local and international students.

\section{REFERENCES}

[1] Ajzen, I \& Fishbein, M. (1980). Understanding Attitudes and Predicting Social Behavior. Englewood Cliffs, NJ: Prentice-Hall.

[2] Arasaratnam, L. A. (2006). Further testing of a new model of intercultural communication competence. Communication 
Research Reports, 23(2), 93-99.

[3] Asgari, M., \&Borzooei, M. (2014). Effects of service quality and price on satisfaction and the consequent learning outcomes of international students. Business and Management, 6(3), 132.

[4] Bartol, K. M., \& Srivastava, A. (2002). Encouraging knowledge sharing: The role of organizational reward systems. Journal of leadership \& organizational studies, 9(1), 64-76. https://doi.org/10.1177/107179190200900105

[5] Bennett, M. J. (1993). Towards ethnorelativism: A developmental model of intercultural sensitivity. Education for the intercultural experience, 2, 21-71.

[6] Bosson, J. K., Johnson, A. B., Niederhoffer, K., \& Swann Jr, W. B. (2006). Interpersonal chemistry through negativity: Bonding by sharing negative attitudes about others. Personal Relationships, 13(2), 135-150. https://doi.org/10.1111/j.1475 $-6811.2006 .00109 . x$.

[7] Byram, M. (1997). Teaching and assessing intercultural communicative competence. Multilingual Matters.

[8] Chen, G. M., \& Starosta, W. J. (1996). Intercultural communication competence: A synthesis. Annals of the International Communication Association, 19(1), 353-383. https://doi.org/10.1080/23808985.1996.11678935.

[9] Chen, G. M., \& Starosta, W. J. (2000). The development and validation of the intercultural sensitivity scale.

[10] Chen, Z., Deng, S., Mamtimin, A., Chang, J., Liu, F., \& Ma, L. (2017, July). Exploring Factors Influencing Knowledge Sharing of International Students at Chinese University. In International Conference on Cross-Cultural Design (pp. 521-530). Springer, Cham.

[11] Choi, J. H., Kim, S., Moon, J. Y., Kang, J., Lee, I., \& Kim, J. (2014). Seek or provide: Comparative effects of online information sharing on seniors' quality of life. Communications of the Association for Information Systems, 34(1), 27.

[12] Chong, C. W., Teh, P. L., \& Tan, B. C. (2014). Knowledge sharing among Malaysian universities' students: do personality traits, class room and technological factors matter? Educational Studies, 40(1), 1-25. doi: 10.1080/03055698.20 13.825577.

[13] Connelly, C. E., \& Kelloway, E. K. (2003). Predictors of employees' perceptions of knowledge sharing cultures. Leadership \& Organization Development Journal.

[14] Daig, I., Herschbach, P., Lehmann, A., Knoll, N., \& Decker, O. (2009). Gender and age differences in domain-specific life satisfaction and the impact of depressive and anxiety symptoms: a general population survey from Germany. Quality of Life Research, 18(6), 669-678.

[15] Davenport, T. H., \& Prusak, L. (1998). Working knowledge: How organizations manage what they know. Harvard Business Press.

[16] De Andrés, V. (1999). Self-esteem in the classroom or the metamorphosis of butterflies. Affect in language learning, 87-102.

[17] Deardorff, D. K. (2006). Identification and assessment of intercultural competence as a student outcome of internationalization. Journal of studies in international education, 10(3), 241-266. doi: 10.1177/1028315306287002.

[18] Desa, A., Yusooff, F., \& Kadir, N. B. Y. A. (2012). Acculturative stress among international postgraduate students at UKM. Procedia-Social and Behavioral Sciences, 59, 364-369.

[19] Diener, E. D., Emmons, R. A., Larsen, R. J., \& Griffin, S. (1985). The satisfaction with life scale. Journal of personality assessment, 49(1), 71-75. http://dx.doi.org/10.1207/s153277 52jpa4901 13

[20] Diener, E., Oishi, S., \& Lucas, R. E. (2003). Personality, culture, and subjective well-being: Emotional and cognitive evaluations of life. Annual review of psychology, 54(1), 403-425.

[21] Dokhtesmati, M., \& Bousari, R. G. (2013). Knowledge Sharing in Iranian academic institutions: Meta-analysis approach. Procedia-Social and Behavioral Sciences, 73, 383-387.

[22] Erdogan, B., Bauer, T. N., Truxillo, D. M., \& Mansfield, L. R. (2012). Whistle while you work: A review of the life satisfaction literature. Journal of management, 38(4), 1038-1083.

[23] Fritz, W., Graf, A., Hentze, J., Möllenberg, A., \& Chen, G. M. (2005). An examination of Chen and Starosta's model of intercultural sensitivity in Germany and United States. https://web.uri.edu/iaics/files/05

[24] Gupta, A. K., \& Govindarajan, V. (2000). Knowledge flows within multinational corporations. Strategic management journal, 21(4),473-496.https://doi.org/10.1002/(SICI)1097-0 $266(200004$.

[25] Hsu, B. F., Wu, W. L., \& Yeh, R. S. (2007, August). Personality composition, affective tie and knowledge sharing: a team level analysis. In PICMET'07-2007 Portland International Conference on Management of Engineering \&Technology (pp. 2583-2592). IEEE.https://doi.org/10.1109 /PICMET.2007.4349592.

[26] Huang, Q., Davison, R. M., \& Gu, J. (2008). Impact of personal and cultural factors on knowledge sharing in China. Asia Pacific Journal of Management, 25(3), 451-471.

[27] Jiang, Z. (2014). Impact of information and communication technology (ICT) on job outcomes: Does knowledge sharing matter. Academy of Taiwan Business Management Review, $10(2), 53-62$.

[28] Kim, Y. Y. (1988). Communication and cross-cultural adaptation: An integrative theory. Multilingual Matters.

[29] Kosheleva, E. Y., Amarnor, A. J., \& Chernobilsky, E. (2015). Stress factors among international and domestic students in Russia. Procedia-Social and Behavioral Sciences, 200, 460-466.

[30] Kowarski, I. (2010). Colleges help students to translate the benefits of study abroad. The Chronicle of Higher Education.

[31] Lin, H. F. (2007). Effects of extrinsic and intrinsic motivation on employee knowledge sharing intentions. Journal of information science, 33(2), 135-149.

[32] Maharaja, G. (2018). The Impact of Study Abroad on College Students' Intercultural Competence and Personal 
Development. International Research and Review, 7(2), $18-41$.

[33] Maharaja, G. (2018). The Impact of Study Abroad on College Students' Intercultural Competence and Personal Development. International Research and Review, 7(2), $18-41$.

[34] Majid, S., \& Wey, S. M. (2011). Knowledge sharing behavior of graduate students. In Global Aspects and Cultural Perspectives on Knowledge Management: Emerging Dimensions (pp. 113-125). IGI Global.

[35] Mak, A. S., Bodycott, P., \& Ramburuth, P. (2015). Beyond host language proficiency: Coping resources predicting international students' satisfaction. Journal of Studies in International Education, 19(5), 460-475. https://doi.org/10.1 $177 / 1028315315587109$

[36] Malaklolunthu, S., \& Selan, P. S. (2011). Adjustment Problems among International Students in Malaysian Private Higher Education Institutions. Procedia Social and Behavioral

Sciences, 15, 833-837. https://doi.org/10.1016/j.sbspro.2011. 03.194 .

[37] Mallasi, H., \& Ainin, S. (2015). Investigating knowledge sharing behaviour in academic environment. Journal of Organizational Knowledge Management, 2015, 1-20.

[38] Ministry of Higher Education. (MOHE). (2017). Higher Education Statistics 2016. Putrajaya: Ministry of Higher Education Malaysia.

[39] Misra, R., \& Castillo, L. G. (2004). Academic Stress among College Students: Camparision of American and International Students. International Journal of Stress Management, 11, 132-148. https://doi.org/10.1037/1072-5245. 11.2.132.

[40] Muda, W. A. M. W. (2008, December). The Malaysian national higher education action plan: Redefining autonomy and academic freedom under the APEX experiment. In ASAIHL Conference, University Autonomy: Interpretation and Variation, UniversitiSains Malaysia, Penang (pp. 12-14).

[41] Nachatar Singh, J. K., Schapper, J., \& Jack, G. (2014). The importance of place for international students' choice of university: A case study at a Malaysian university. Journal of Studies in International Education, 18(5), 463-474.

[42] Novak, J. D. (2010). Learning, creating, and using knowledge: Concept maps as facilitative tools in schools and corporations. Routledge.

[43] Peng, S. Y. (2006). A comparative perspective of intercultural sensitivity between college students and multinational employees in China. Multicultural perspectives, 8(3), 38-45. https://doi.org/10.1207/s15327892mcp0803_7

[44] Peng, S. Y., Rangsipaht, S., \& Thaipakdee, S. (2005). Measuring intercultural sensitivity: A comparative study of ethnic Chinese and Thai nationals. Journal of Intercultural Communication Research, 34(2), 119-137.

[45] Rafaeli, S., \& Ravid, G. (2003). Information sharing as enabler for the virtual team: an experimental approach to assessing the role of electronic mail in disintermediation. Information Systems Journal, 13(2), 191-206.

[46] Rienties, B., Beausaert, S., Grohnert, T., Niemantsverdriet, S., \& Kommers, P. (2012). Understanding academic performance of international students: The role of ethnicity, academic and social integration. Higher education, 63(6), 685-700. https://doi.org/10.1007/s10734-011-9468-1

[47] Ryff, C. D. (1989). Happiness is everything, or is it? Explorations on the meaning of psychological well-being. Journal of personality and social psychology, 57(6), 1069. https://doi.org/10.1037//0022-3514.57.6.1069

[48] Sarwari, A. Q., \& Abdul Wahab, M. N. (2017). Study of the relationship between intercultural sensitivity and intercultural communication competence among international postgraduate students: A case study at University Malaysia Pahang. Cogent Social Sciences, 3(1), 1310479.

[49] Shawaqfeh, B., \& Almahaireh, A. (2019). TechnoWellness and Its Relationship with Happiness and Optimism among University of Jordan Students. Journal of Social Studies Education Research, 10(2), 145-167.

[50] Shin, D. C., \& Johnson, D. M. (1978). Avowed happiness as an overall assessment of the quality of life. Social indicators research, 5(1-4), 475-492. https://doi.org/10.1007/BF003529 44.

[51] Sim, M. W. (2006). Information and knowledge sharing among postgraduate students in Singapore (Doctoral dissertation).

[52] Sinicrope, C., Norris, J., \& Watanabe, Y. (2007). Understanding and assessing intercultural competence: A summary of theory, research, and practice (technical report for the foreign language program evaluation project). University of Hawai'I Second Langauge Studies Paper 26 (1).

[53] Smith, R. A., \& Khawaja, N. G. (2011). A review of the acculturation experiences of international students. International Journal of intercultural relations, 35(6), 699-713. https://doi.org/10.1016/j.ijintrel.2011.08.004.

[54] Sosik, J. J., \& Jung, D. I. (2002). Work-group characteristics and performance in collectivistic and individualistic cultures. The Journal of social psychology, 142(1), 5-23.

[55] Suh, E., Diener, E., Oishi, S., \&Triandis, H. C. (1998). The shifting basis of life satisfaction judgments across cultures: Emotions versus norms. Journal of personality and social psychology, 74(2), 482.

[56] Summers, M., \&Volet, S. (2008). Students' attitudes towards culturally mixed groups on international campuses: impact of participation in diverse and non-diverse groups. Studies in higher education, 33(4), 357-370.

[57] Syed-Ikhsan, S. O. S. B., \& Rowland, F. (2004). Benchmarking knowledge management in a public organisation in Malaysia. Benchmarking: an international journal, 11(3), 238-266.

[58] Tamam, E. (2010). Examining Chen and Starosta's model of intercultural sensitivity in a multiracial collectivistic country. Journal of Intercultural Communication Research, 39(3), 173-183. https://doi.org/10.1080/17475759.2010.534860.

[59] Vazirani, S., Carmona, C., Vidal, J., Hernaiz-Agreda, N., López-Francés, I., \& Jesús Benlloch-Sanchis, M. (2018). International Students' Integration in Classroom: Strategies and Support by Teachers and Local Students in Higher Education.

[60] Wang, S., \& Noe, R. A. (2010). Knowledge sharing: A review 
and directions for future research. Human resource management review, 20(2), 115-131.

[61] Wasko, M. M., \& Faraj, S. (2005). Why should I share? Examining social capital and knowledge contribution in electronic networks of practice. MIS quarterly, 35-57.

[62] Wilson, J., Ward, C., \& Fischer, R. (2013). Beyond culture learning theory: What can personality tell us about cultural competence?. Journal of cross-cultural psychology, 44(6), 900-927.

[63] Woodward, R. (2009). The organisation for economic co-operation and development (OECD). Routledge.

[64] Wu, J. F. (2015). Examining Chen and Starosta's model of intercultural sensitivity in the Taiwanese cultural context. International Journal of Modern Education and Computer Science, 7(6), 1. https://doi.org/10.5815/ijmecs.2015.06.01.

[65] Yee, C. P., \& Mokhtar, A. H. A. (2013). International students' learning experiences at private higher education institutions in Malaysia. Proceedings of the Global Summit on Education, Kuala Lumpur, March, 11-12.

[66] Yuen, T. J., \& Majid, M. S. (2007). Knowledge-sharing patterns of undergraduate students in Singapore. Library Review.https://doi.org/10.1108/00242530710760382. 